\title{
MODEL VERSUS NATURE: HYDRODYNAMICS IN MANGROVE PNEUMATOPHORES
}

\author{
Erik M. Horstman ${ }^{1}$, Karin R. Bryan ${ }^{1}$, Julia C. Mullarney ${ }^{1}$ and Conrad A. Pilditch ${ }^{1}$
}

\begin{abstract}
Water flows through submerged and emergent vegetation control the transport and deposition of sediment in coastal wetlands. Many past studies into the hydrodynamics of vegetation fields have used idealized vegetation mimics, mostly rigid dowels of uniform height. In this study, a canopy of real mangrove pneumatophores was reconstructed in a flume to quantify flow and turbulence within and above this canopy. At a constant flow forcing, an increase in pneumatophore density, from $71 \mathrm{~m}^{-2}$ to $268 \mathrm{~m}^{-2}$, was found to cause a reduction of the within-canopy flow velocities, whereas the over-canopy flows increased. Within-canopy velocities reduced to $46 \%$ and $27 \%$ of the free-stream velocities for the lowest and highest pneumatophore densities, respectively, resulting in stronger vertical shear and hence greater turbulence production around the top of the denser pneumatophore canopies. The maximum Reynolds stress was observed at 1.5 times the average pneumatophore height, in contrast to uniform-height canopies, in which the maximum occurs at approximately the height of the vegetation. The ratios of the within-canopy velocity to the free-stream velocity for the pneumatophores were found to be similar to previous observations with uniform-height vegetation mimics for the same vegetation densities. However, maxima of the scaled friction velocity were two times smaller over the real pneumatophore canopies than for idealized dowel canopies, due to the reduced velocity gradients over the variable-height pneumatophores compared to uniform-height dowels. These findings imply that results from previous studies with idealized and uniform vegetation mimics may have limited application when considering sediment transport and deposition in real vegetation, as the observed turbulence characteristics in nonuniform canopies deviate significantly from those in dowel canopies.
\end{abstract}

Keywords: vegetated flows; pneumatophores; flume experiments; flow profiles; turbulence production

\section{INTRODUCTION}

Aquatic vegetation imposes a significant drag force on the ambient water, altering the transport of both water and suspended matter. Hence, water motions through vegetation canopies have been widely studied (reviewed by e.g. Mazda and Wolanski, 2009; Nepf, 2012; Tempest et al., 2015). In the case of uniform emergent vegetation, reduced current velocities are found to be approximately constant over the water depth, except in the near-bed region where additional bed shear causes a local velocity peak (Liu et al., 2008; Nepf, 1999; Yager and Schmeeckle, 2013). The velocity within emergent vegetation monotonically decreases with the vegetation density $\left(a d=N d^{2}\right.$, wherein $N$ is the number of stems per unit area and $d$ the stem diameter), the water depth-to-stem diameter ratio $(H / d)$ and the surface roughness $\left(C_{D}\right)$ of the vegetation elements (Liu et al., 2008; Nepf, 1999). The turbulence intensity, expressed as the square-root of the turbulent kinetic energy divided by the flow velocity, $k^{1 / 2} / u$, is constant over depth outside the bed-shear layer, similar to the velocity profile (Liu et al., 2008). While turbulence intensity increases with the presence of sparse emergent vegetation, a critical vegetation density exists beyond which the turbulence decreases because of the reduction in velocity with increased density (Nepf, 1999).

Within-canopy velocities also tend to be constant with depth in submerged canopies of uniform vegetation elements. Above a submerged canopy with height $h_{c}$, a characteristic logarithmic velocity profile develops for depth ratios $H / h_{c}>1.25$ (Liu et al., 2008; Nepf and Vivoni, 2000), with an inflection point close to the top of the canopy. Often Kelvin-Helmholtz vortices are generated in this canopy shear layer, giving rise to a dynamic mixing layer and a local peak in the turbulence profile (Chen et al., 2013; Liu et al., 2008; Raupach et al., 1996). As with emergent canopies, the elevation of the logarithmic velocity profile with respect to the top of the submerged vegetation, and consequently the penetration depth of the turbulence into the vegetation, depends on the vegetation density, the relative height of the vegetation $\left(H / h_{c}\right)$ and the surface roughness of the vegetation elements (Liu et al., 2008; Lowe et al., 2005; Nepf and Vivoni, 2000).

Previous work on drag forces and turbulence generation and dissipation in vegetation canopies have mostly used uniform, rigid cylindrical dowels in various arrangements (random, staggered or aligned) to mimic aquatic vegetation (Chen et al., 2013; Dunn et al., 1996; Liu et al., 2008; Lowe et al., 2005; Murphy et al., 2007; Tanino and Nepf, 2008; White and Nepf, 2007). Some similar studies have also used real canopies of flexible vegetation (Järvelä, 2005; Lacy and Wyllie-Echeverria, 2011; Sukhodolova and Sukhodolov, 2012); however, their results are often affected by an inability to resolve 
the hydrodynamics within the irregular and dynamic vegetation. This difficulty in obtaining measurements means the effects of non-homogeneous vegetation properties on the hydrodynamics remain largely unquantified.

To address this knowledge gap, Liu et al. (2010) studied flow patterns with a submerged and idealized double-layer rigid vegetation canopy, consisting of two heights of acrylic dowels. Throughout their experiments, the canopy consisted of various densities of regularly spaced short and tall dowels with the tall dowels being 1.5, 2 or 3 times higher than the shorter ones. For sufficiently dense dowel configurations and a large height difference between the short and tall dowels, the velocity profile in these composite canopies resembled a superposition of the velocity and turbulence profiles for single layer submerged canopies. Yet, the shear across the top of each of the vegetation layers individually was reduced compared to the shear at the top of a uniform-height dowel canopy of the same density, lowering the peak turbulence production.

Previous studies have elucidated key principles of the hydrodynamics in idealized uniform-height and composite double-layer vegetation canopies. However, natural canopies often exhibit substantial heterogeneity in vegetation characteristics. Mangrove pneumatophores are woody aerial roots, growing upward from shallow lateral root systems of e.g. Avicennia and Sonneratia species, and typically have heights ranging from a few centimetres to decimetres (Tomlinson, 1986). Sonneratia pneumatophores are generally thicker and taller and have a flaky bark, whereas Avicennia pneumatophores usually extend less than $30 \mathrm{~cm}$ above the surface and tend to have a smooth surface (Tomlinson, 1986). Nevertheless, pneumatophore heights and diameters can vary substantially within the same field site (e.g. Horstman et al., 2014; Liénard et al., 2016).

The present study addresses the hydrodynamics in a natural pneumatophore canopy through a series of flume experiments with three different densities of reconstructed Avicennia pneumatophore canopies. The aim of this work was to explore (i) the impact of pneumatophore density on the hydrodynamics within and above the vegetation canopy, and (ii) the differences of the hydrodynamics in real pneumatophore canopies compared to the hydrodynamic effects of idealized rigid dowel canopies that were employed in previous studies.

\section{EXPERIMENTAL SETUP}

Experiments were conducted in a $6.6 \mathrm{~m}$ long and $0.5 \mathrm{~m}$ wide recirculating acrylic flume. Flow was generated by a variable-frequency impeller, mounted in the recirculating duct. An insert of $0.3 \mathrm{~m}$ long stacked $20 \mathrm{~mm}$ diameter PVC tubes was used to dampen turbulence at the entrance of the flume. Pneumatophores were mounted in large sheets of floral foam that were incorporated in the false floor of the flume. The pneumatophores canopy extended across the full width of the flume and was $4.0 \mathrm{~m}$ long, starting $0.45 \mathrm{~m}$ downstream of the flow rectifier (Figure 1a). A fully automated 3D positioning table (Animatics SmartMotors) allowed for precise positioning and accurate repetitions of hydrodynamic measurements.

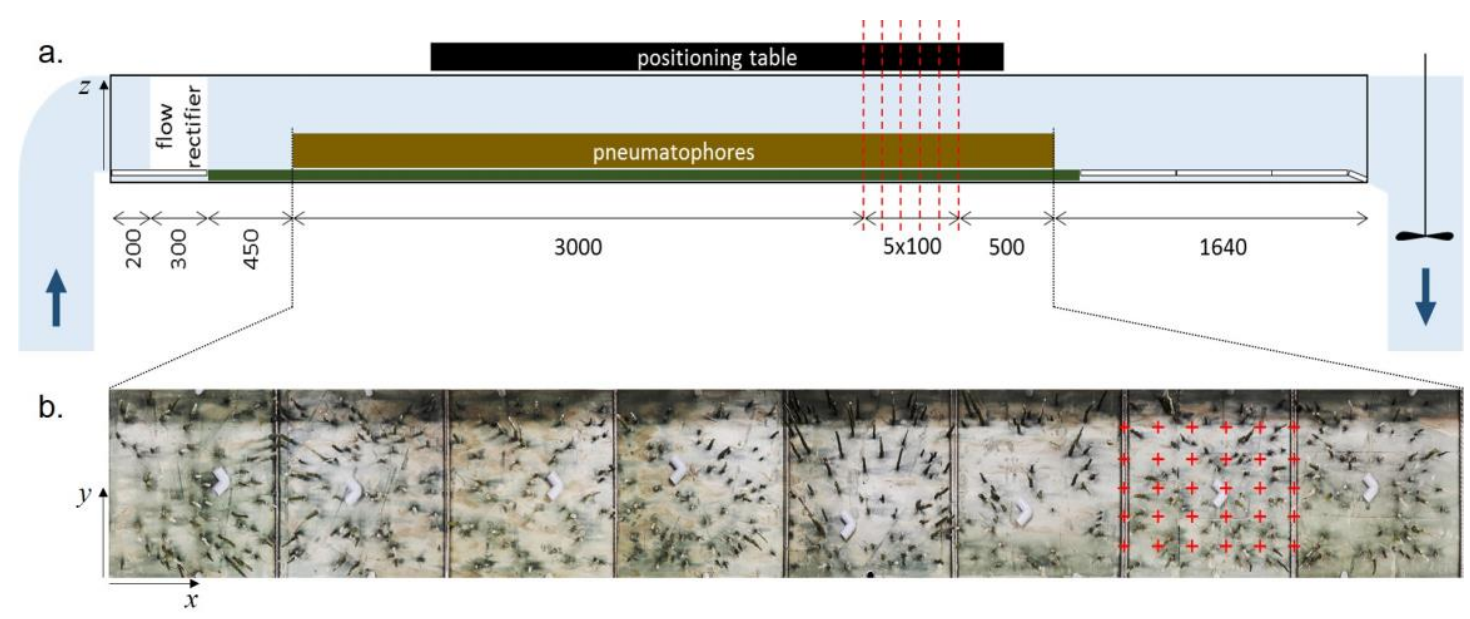

Figure 1. (a) Side view of the flume (dimensions in $\mathrm{mm}$ ) and (b) top view of the reconstructed high-density pneumatophore canopy. Locations of data collection are marked with dashed lines in the side view and red + symbols in the top view. (Lateral rods and pipe elbows in the top view were included for reconstruction purposes and were not present during the experiments.) 

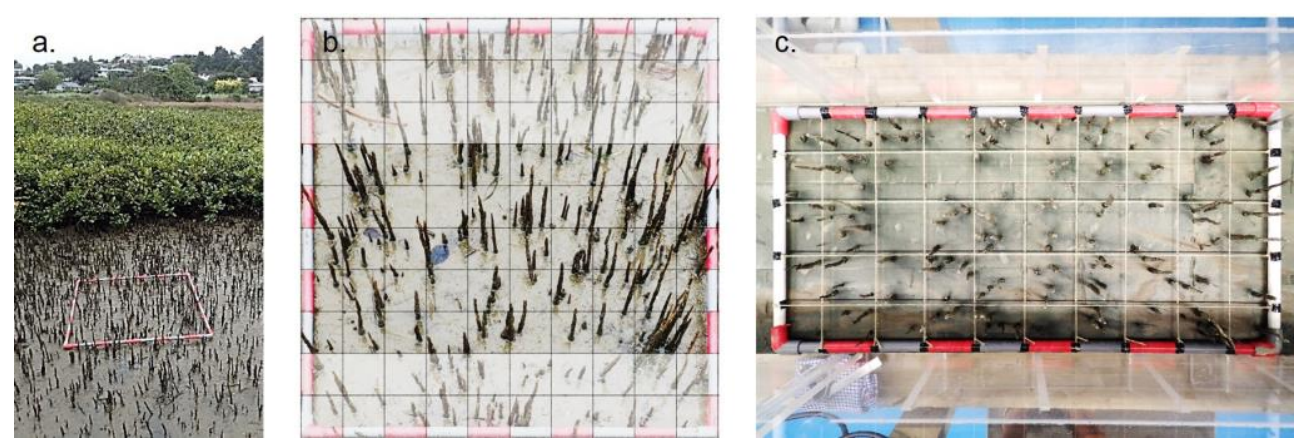

Figure 2. Canopy reconstruction in the flume: (a) high-density pneumatophore cover in the Waikareao Estuary in New Zealand, (b) part of the rectified photograph resulting from the field survey and (c) reconstructed canopy in the flume.

Experiments were run for a plane bed (PB) scenario and for three canopies composed of real pneumatophores harvested from the Waikareao Estuary, Tauranga Harbour, New Zealand. In order to obtain a natural spread of the pneumatophores in the flume, scaled photographs of $1 \times 4 \mathrm{~m}^{2}$ patches of sparse, average and dense pneumatophore covers were collected at the field site (Figure 2a), prior to harvesting. These surveys revealed a patchiness of the pneumatophores that was reconstructed in the flume by applying a $10 \times 10 \mathrm{~cm}^{2}$ raster overlay on both the photo reconstruction and the flume bed (Figure 2b-c). The reconstructed pneumatophore canopies had low (LD), average (AD) and high (HD) densities $N$ of 71, 154 and $268 \mathrm{~m}^{-2}$, respectively. The pneumatophores generally had a tapered shape with an average diameter at the bed of $8.1 \mathrm{~mm}$, decreasing to $6.6 \mathrm{~mm}$ at mid-height and $4.0 \mathrm{~mm}$ at the tip of the pneumatophore, making for a mean diameter $d$ of $6.2 \mathrm{~mm}$. The resulting mean cross-sectional densities $\varphi=N \pi d^{2} / 4$ ranged from 0.0023 to 0.0086 for the low and high pneumatophore densities, respectively (Table 1). Although the mean pneumatophore diameter remained constant throughout all three reconstructions, the average pneumatophore heights $h_{c}$ between densities differed slightly (Table $1)$.

The water depth in the flume experiments was maintained at $30 \mathrm{~cm}$. Consequently, the ratios of water depth $H$ to canopy height $h_{c}$ ranged from 4.2 to 4.7 (Table 2). For each density, experiments were run at two fixed impeller frequencies that generated free-stream flow velocities of $10 \mathrm{~cm} / \mathrm{s}$ and $15 \mathrm{~cm} / \mathrm{s}$ in the experiments without pneumatophores (PB; Table 2). Impeller settings were not modified after the introduction of the canopies, as to maintain a constant flow forcing throughout experiments with the same flow rate.

\section{DATA COLLECTION \& PROCESSING}

Flow data were collected with a Nortek Vectrino Profiler $(10 \mathrm{MHz})$ that was mounted on the positioning table. Velocity profiles comprising 35 vertical cells of $1 \mathrm{~mm}$, starting at $40 \mathrm{~mm}$ below the probe, were collected at $50 \mathrm{~Hz}$. To account for the inhomogeneity of the velocity field inside and above the canopy, vertical velocity profiles were collected at 30 horizontal positions within the data collection window that was located between 3.0 and $3.5 \mathrm{~m}$ into the vegetation field (Figure 1). These vertical profiles were collected at 6 locations with a $100 \mathrm{~mm}$ interval in the streamwise $x$-direction and at 5 positions with a $75 \mathrm{~mm}$ spacing in the lateral $y$-direction. Vertical increments in the instrument's $z$ position were set to $45 \mathrm{~mm}$, supposedly resulting in close-to continuous velocity profiles. For the plane bed experiments, averaging was used to account for imperfections in the flume. In these experiments, the streamwise spacing was increased to $500 \mathrm{~mm}$ and only 10 vertical velocity profiles were collected within the data collection window.

Table 1. Vegetation properties of the flume experiments (values for $d$ and $h_{c}$ present mean \pm standard deviation)

\begin{tabular}{|l|c|c|c|}
\hline & $\begin{array}{c}\text { low density } \\
\text { LD }\end{array}$ & $\begin{array}{c}\text { average density } \\
\text { AD }\end{array}$ & $\begin{array}{c}\text { high density } \\
\text { HD }\end{array}$ \\
\hline$N\left[\mathrm{~m}^{-2}\right]$ & 71 & 154 & 268 \\
$d[\mathrm{~mm}]$ & $6.2 \pm 1.4$ & $6.2 \pm 1.4$ & $6.2 \pm 1.4$ \\
$h_{c}[\mathrm{~mm}]$ & $64 \pm 25$ & $65 \pm 34$ & $71 \pm 38$ \\
$\varphi[-]$ & 0.0023 & 0.0049 & 0.0086 \\
\hline
\end{tabular}


Table 2. Experimental conditions.

\begin{tabular}{|l|c|c|c|c|c|}
\hline & $\begin{array}{c}\boldsymbol{H} \\
{[\mathbf{m}]}\end{array}$ & $\begin{array}{c}\boldsymbol{H} / \boldsymbol{h}_{\boldsymbol{c}} \\
{[-]}\end{array}$ & $\begin{array}{c}\boldsymbol{U}_{\infty} \mathbf{1}^{\mathbf{m}}[\mathbf{s}] \\
{[\mathbf{m}]}\end{array}$ & $\begin{array}{c}\boldsymbol{U}_{c}\left(\mathbf{U}_{0}\right)^{2} \\
{[\mathbf{m} / \mathbf{s}]}\end{array}$ & $\begin{array}{c}\boldsymbol{U}_{c} / \mathbf{U}_{\infty} \\
{[\mathbf{m} / \mathbf{s}]}\end{array}$ \\
\hline PB_H30_V10 & 0.30 & - & 0.10 & 0.06 & - \\
PB_H30_V15 & 0.30 & - & 0.15 & 0.10 & - \\
LD_H30_V10 & 0.30 & 4.7 & 0.11 & 0.05 & 0.46 \\
LD_H30_V15 & 0.30 & 4.7 & 0.16 & 0.07 & 0.46 \\
AD_H30_V10 & 0.30 & 4.6 & 0.11 & 0.04 & 0.36 \\
AD_H30_V15 & 0.30 & 4.6 & 0.17 & 0.06 & 0.36 \\
HD_H30_V10 & 0.30 & 4.2 & 0.12 & 0.03 & 0.26 \\
HD_H30_V15 & 0.30 & 4.2 & 0.18 & 0.05 & 0.27 \\
\hline
\end{tabular}

${ }^{1}$ Free-stream velocity at $5 \mathrm{~cm}$ below the water surface.

2 Depth-averaged velocities for $0 \leq z \leq h_{c}$ are denoted $U_{c}$ for the vegetated experiments and $U_{0}$ for the plane bed experiments.

Three pre-processing procedures were applied to the Vectrino data in order to improve data quality. Firstly, all data were transformed according to an improved calibration matrix provided by Nortek directly after completion of the experiments. Secondly, the transformed data were filtered for correlations $\geq 70 \%$ and signal-to-noise ratios $\geq 15 \mathrm{~dB}$ (cf. Rusello et al., 2006). Lastly, the Doppler noise removal procedure of Hurther \& Lemmin (2001) was applied. This procedure corrects for the noise in the turbulent velocities by compensating for the covariance between the two vertical velocity signals that are obtained by the Vectrino. Despite this elaborate data pre-processing scheme, turbulence profiles in the present study showed substantial variability along the vertical (see e.g. Figure 5b). Consequently, for turbulent properties this paper focusses on the single-point observations deemed to be most reliable (in the 'sweet spot') located at $50 \mathrm{~mm}$ below the probe (Nortek, 2011), thus producing intermittent data profiles with a vertical spacing of $45 \mathrm{~mm}$.

Time-averaged $(\bar{u}, \bar{v}, \bar{w})$ and turbulent $\left(u^{\prime}, v^{\prime}, w^{\prime}\right)$ velocities were extracted from each preprocessed data record, with $u, v$ and $w$ denoting the streamwise, spanwise and vertical velocity components, respectively. Turbulent kinetic energy $k=1 / 2\left(u^{\prime 2}+v^{\prime 2}+w^{\prime 2}\right)$ and Reynolds stress $u^{\prime} w^{\prime}$ (i.e. Reynolds shear stress normalized by $\rho$ ) were computed for every data record. Parameters were timeaveraged over the length of the data records (denoted with overbars) and spatial averages (denoted with angle brackets) were obtained by averaging over all 30 vertical profiles (Figure 1b), or 10 profiles for the PB experiments.

The free-stream velocity over the canopy $U_{\infty}$ was defined as the (spatially-averaged) velocity observed nearest to the water surface, i.e. at $5 \mathrm{~cm}$ below the water surface due to the instrument's blanking distance and a minimum submergence of $1 \mathrm{~cm}$. For the depth-averaged velocity within the canopy $U_{c}$, the spatially-averaged velocity profiles were linearly interpolated across the gap between each consecutive profile along the vertical and velocities were then averaged over $0 \leq z \leq h_{c}$. For the PB experiments the same procedure was applied to obtain the equivalent average velocity $U_{0}$.

\section{RESULTS}

\section{Spatial variability in pneumatophore canopies}

The patchiness of the pneumatophore canopy gave rise to noticeable local variations in the streamwise flow velocities, in the horizontal as well as in the vertical plane (Figure 3). For the densest canopy, patches of pneumatophores were located just upstream of $(x, y)=(3.00,0.175),(3.20,0.100)$ and (3.30,0.325) (Figure 2). These concentrations of roughness elements gave rise to local downstream flow decelerations (Figure 3a-c). However, the vertical extent of these decelerations varied due to the nonuniform height of the pneumatophores. This result was clearly visible, for example at $(x, y)=$ $(3.30,0.100)$, where a pronounced deceleration was observed near the bed at $z / h_{c}=0.21$ (Figure 3a). However, higher in and above the canopy, this local reduction in flow speeds was less pronounced (Figure 3b-c). This variation in flow speed throughout the canopy was also observed in the lateral crosssections in Figure 3d-f, indicating a clear deviation from the well-defined and constricted canopy shear layers over uniform-height canopies presented in previous studies (e.g. Bouma et al., 2007; Nepf and Vivoni, 2000). 

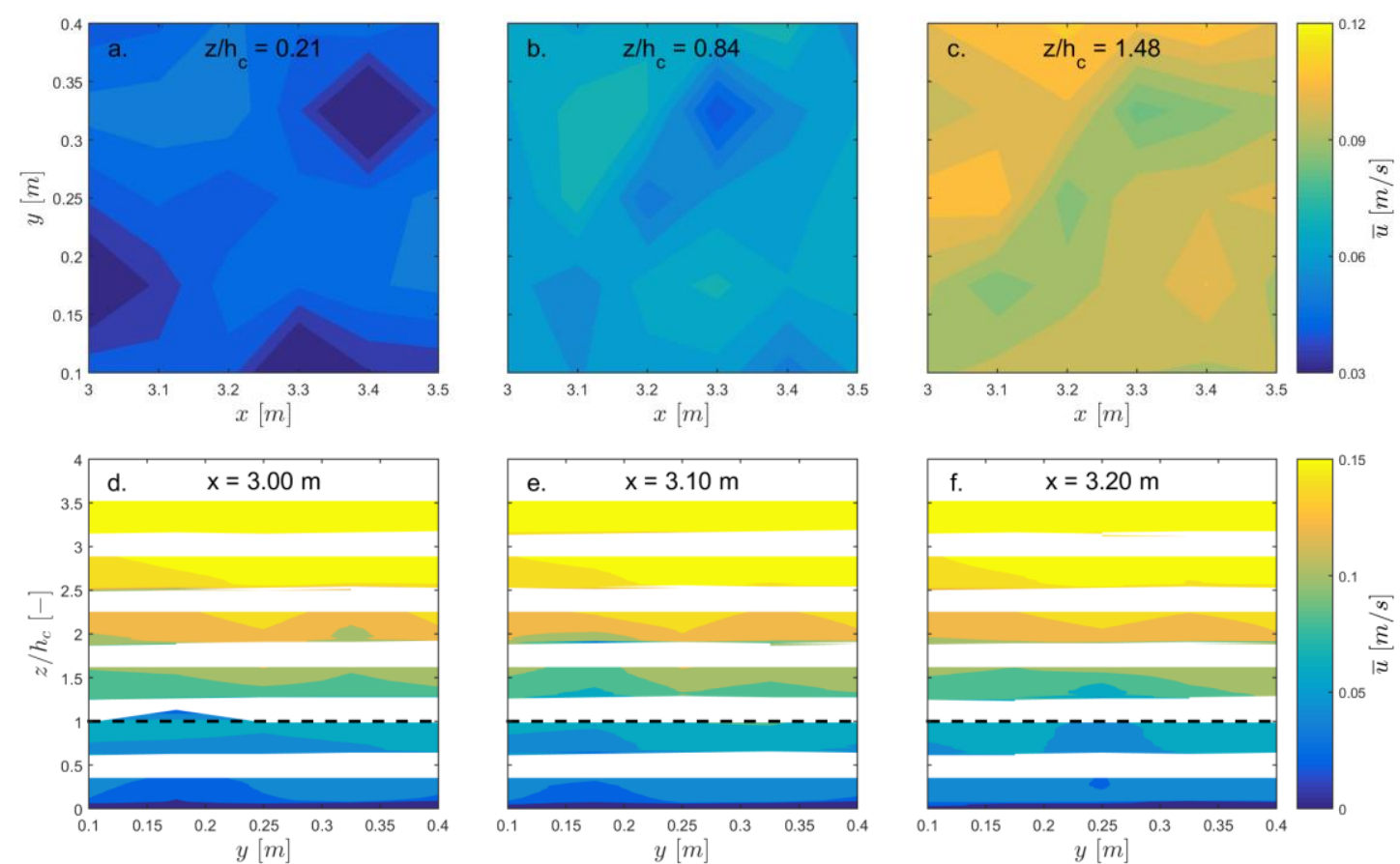

Figure 3. Streamwise velocities plotted along (a-c) horizontal and (d-f) vertical cross-sections of the flume, for the high density experiment with the high flow forcing (HD_H30_V15 in Table 1). Horizontal crosssections are presented for heights of (a) $1.5 \mathrm{~cm}$, (b) $6.0 \mathrm{~cm}$, and (c) $10.5 \mathrm{~cm}$ above the bed. Vertical crosssections are given for distances (d) $3.00 \mathrm{~m}$, (e) $3.10 \mathrm{~m}$ and (f) $3.20 \mathrm{~m}$ from the leading canopy edge. Dashed lines indicate the average canopy height. (Note the different scales of the color bars for the upper and lower panels.)

A comparison of the spatial variability of the streamwise velocities near the top of the canopy $\left(z / h_{c}\right.$ $=0.84$ ), showed that the relative variance of these velocities was smallest for the average pneumatophore density (Figure 4). At the low pneumatophore density, few but relatively large fluctuations of the streamwise velocities were observed, as the pneumatophores locally caused strong reductions of the relatively high within-canopy velocities (Figure 5a). Conversely, the great number of pneumatophores in the densest canopy caused the within-canopy velocity to drop and hence local fluctuations around the pneumatophores were smaller. At the average pneumatophore density, these two effects merged. Within-canopy velocity variability was more limited by the vegetation roughness than within a sparse canopy due to the reduced within-canopy velocity, whereas the smaller number of pneumatophores for the average density canopy compared to the densest canopy limited the amount of velocity fluctuations near the top of the canopy. This trend was observed for both flow regimes (Figure 4) and is similar to previous findings by Nepf (1999) that the turbulence maximum initially increases with increasing canopy density, but eventually decreases if the canopy density increases beyond a certain threshold.

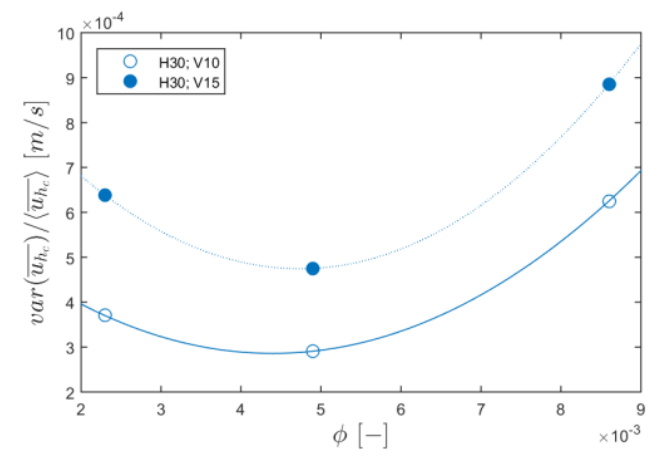

Figure 4. Variance of the streamwise velocity, normalized by the spatially averaged streamwise velocity, near the top of the pneumatophore canopy $\left(z=0.84 h_{c}\right)$. Water depth $(\mathrm{H} 30)$ and flow forcing $(\mathrm{V} 10 / \mathrm{V} 15)$ conditions as presented in Table 2. 


\section{Density effects in pneumatophore canopies}

Compared to the plane bed scenario, the introduction of the pneumatophore canopy caused a significant reduction of the within-canopy streamwise velocities (Figure 5a). Spatially averaged velocities within the pneumatophore canopy $U_{c}$ decreased by up to about $25 \%, 38 \%$ and $53 \%$ compared to the plane bed velocities $U_{0}$ in the same region, for the low, average and high pneumatophore densities, respectively (Table 2). Velocity reductions extended to about two times the average pneumatophore height, above which enhanced flow velocities were observed compared to the plane bed scenario (Figure 5a). The distortion of the vertical flow profile due to the pneumatophore canopy was expressed by the ratio of the within-canopy velocity $U_{c}$ to the free-stream velocity $U_{\infty}$ (cf. Lowe et al., 2005). For the experiments with $30 \mathrm{~cm}$ water depth, these ratios decreased from 0.46 for the lowest pneumatophore density to 0.27 for the highest pneumatophore density (Table 2). For comparison, for the standard logarithmic velocity profiles for the plane bed scenario the ratio of $U_{0}$ to $U_{\infty}$ was 0.65 at the same water depth.

The larger differences between near-bed and free-stream velocities with the increasing pneumatophore densities gave rise to a significant production of vertical shear around the top of the vegetation canopy (Figure 5b-c). Kelvin-Helmholtz vortices triggered by the vertical velocity gradient over the top of the canopy caused a local increase of the turbulence and Reynolds stress (Nepf and Vivoni, 2000). This turbulence generation was quite pronounced for all canopy densities, but was further enhanced by the greater velocity gradients over the denser canopies. Turbulence maxima, particularly for the higher pneumatophore densities, were observed at around $z=1.5 h_{c}$ (Figure $5 \mathrm{~b}-\mathrm{c}$ ), as opposed to these maxima occurring around $z=h_{c}$ in studies with uniform canopy heights (e.g. Chen et al., 2013; Nepf and Vivoni, 2000; Poggi et al., 2004). Regardless of the increase of the turbulence maxima in the vegetated scenarios, the near-bed Reynolds stresses showed a continuous decrease as the vegetation densities increased, due to the lower within-canopy velocities (Figure 5c).
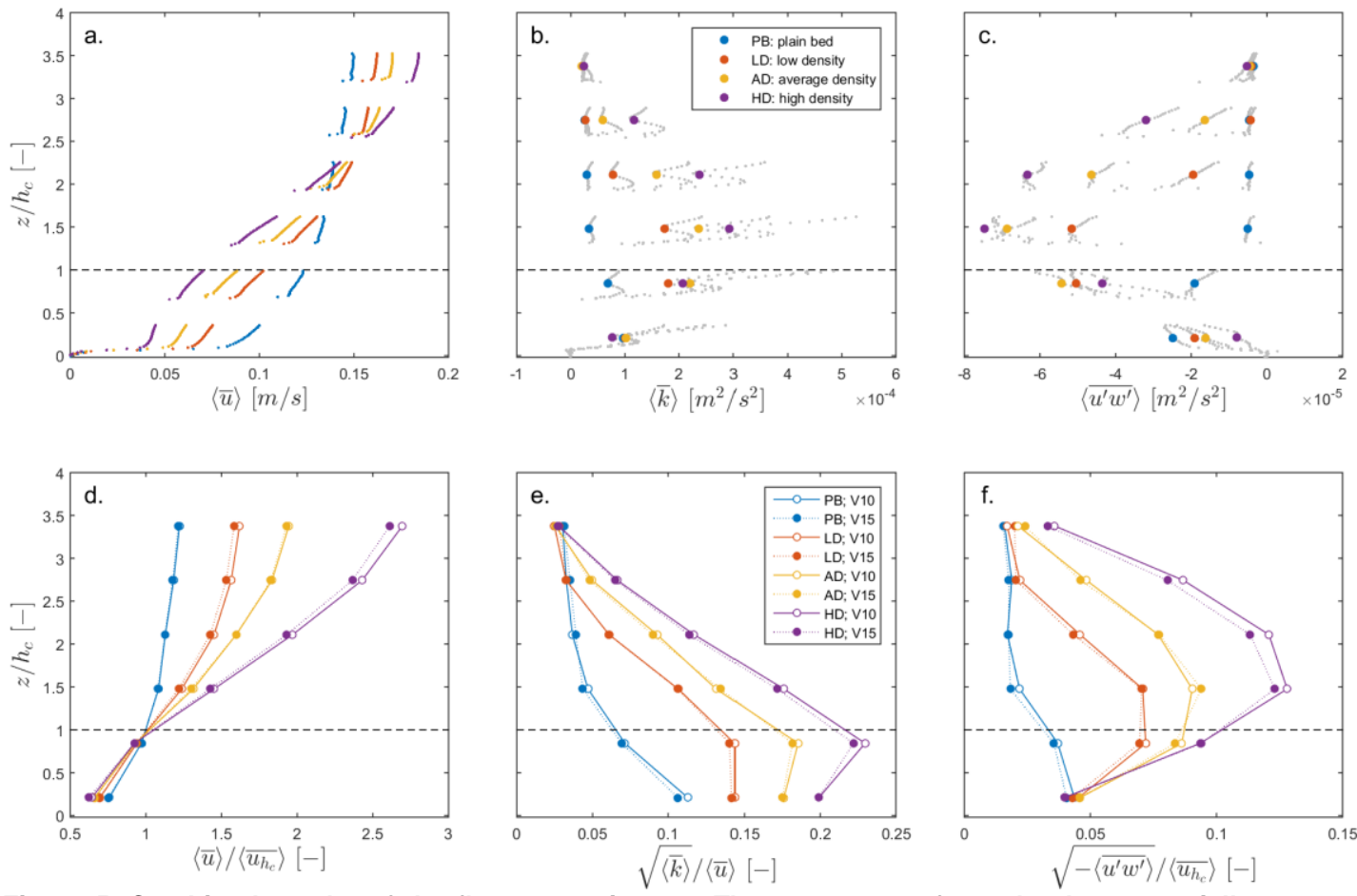

Figure 5. Combined results of the flume experiments. The upper row of panels shows spatially-averaged vertical profiles of (a) the streamwise velocity, (b) the turbulent kinetic energy, and (c) the Reynolds stress, for increasing densities of the vegetation canopy, all for the high flow scenario (V15). The lower row of panels presents spatially-averaged vertical profiles of (d) the streamwise velocity scaled with the velocity at the top of the canopy, (e) the turbulence intensity, and (f) the friction velocity scaled with the velocity at the top of the canopy, for all canopy densities, at both the low flow (V10; open symbols) and high flow (V15; solid symbols) scenarios. Panels $b$ and $c$ present the reliable turbulence observations in the sweet spots (solid symbols) and the noise-affected observations throughout the remainder of the observed profiles (grey dots; see 'Data Collection and Processing'). The dashed line in each panel indicates the average canopy height. 


\section{Flow regime effects in pneumatophore canopies}

Impacts of the flow forcing were found to be negligible. Streamwise velocity profiles that were scaled with the velocity at the top of the pneumatophore canopy $\left\langle\overline{u_{h_{c}}}\right\rangle$ collapsed perfectly for the low and high flow forcing (Figure 5d). This resemblance is in agreement with previous observations by Dunn et al. (1996) for a broad range of flow conditions. Consequently, the velocity ratios $U_{c} / U_{\infty}$ were similar between the experiments with the low and high flow forcing when all other factors were kept equal (Table 2).

Turbulence profiles obtained from the different experiments were scaled with the streamwise velocity as well. Here, the turbulent kinetic energy was scaled with the streamwise velocity at the same height, producing profiles of the turbulence intensity $\sqrt{\langle\bar{k}\rangle} /\langle\bar{u}\rangle$. The Reynolds stress was converted to a friction velocity $\sqrt{-\left\langle\overline{u^{\prime} w^{\prime}}\right\rangle}$ which was then scaled with the velocity at the top of the canopy. The resulting profiles of the turbulent kinetic energy and the scaled Reynolds stress produced overlapping profiles for both flow conditions at each of the canopy densities (Figure 5e-f). Hence, the changes to both the streamwise velocities and the turbulence magnitudes were directly related with the increase of the velocity at the top of the pneumatophore canopy for the increased flow forcing, without causing any changes in the vertical profiles of these properties.

\section{DISCUSSION}

\section{Comparison of pneumatophores with uniform dowel canopies}

An abundance of data on flows through artificial canopies exists, mostly from experiments with canopies consisting of rigid, uniform-height dowels. The within-canopy velocity is a common parameter in these studies, either depth-averaged over the height of the canopy (e.g. Murphy et al., 2007) or as the constant velocity below the canopy shear layer (e.g. Ghisalberti and Nepf, 2004). Within-canopy velocities are generally compared to the free-stream velocities above the canopy (e.g. Ghisalberti and Nepf, 2004; Lowe et al., 2005).

Data from prior studies by Dunn et al. (1996), Ghisalberti and Nepf (2004), Lowe et al. (2005), Murphy et al. (2007) and Chen et al. (2013) have been assembled and analyzed, covering 62 experiments that encompass a wide range of canopy densities and submergence ratios. To enable the comparison of these results, an adjusted vegetation density was defined as the product of the vegetation density $\varphi$ and the submergence ratio $H / h_{c}$. All compiled experiments considered uniform-height dowels. The results, summarized in Figure 6a, show that the calculated (or estimated) ratios of the withincanopy velocity to the free-stream velocity above the vegetation $U_{c} / U_{\infty}$ are negatively and significantly correlated with the depth-adjusted vegetation density $\varphi\left(H / h_{c}\right)$. The ratio of the within-canopy velocity to the free-stream velocity for the non-uniform variable-height pneumatophore experiments collapsed well onto the data obtained from the previous experiments with uniform-height dowels (Figure 6a). Throughout all data from the present and previous studies, an increasing density or an increasing submergence ratio of the canopy, or a combination thereof, caused a non-linear decrease of the ratio $U_{c} / U_{\infty}$ according to the following relationship:

$$
U_{c} / U_{\infty}=0.13\left(\varphi\left(H / h_{c}\right)\right)^{-0.31}
$$

Given the similarity of the ratios of the within-canopy velocity to the free-stream velocity in the pneumatophore canopies with those previously observed in uniform-height dowel canopies, it can be concluded that the variable shape and height of the pneumatophores in this study does not instigate a significantly different vertical distribution of the streamwise velocities than the idealized uniform-height dowels in those previous studies.

This similarity between the experiments with dowels and with pneumatophores does not apply to the turbulence in the canopy shear layer. The maximum of the spatially averaged friction velocity, i.e. the square-root of the maximum absolute value of the Reynolds shear, scaled with the free-stream velocity, was found to be more or less constant over the full range of conditions in the compiled series of experiments, with a mean value of 0.108 (Figure 6b). This finding was consistent with Lowe et al.'s (2005) observation that the canopy-induced friction velocity scaled by the free stream velocity was about 0.1 throughout their experiments. However, the observations from the present experiments with real pneumatophores produced a mean of 0.048 for the maximum shear velocity relative to the free- 
stream velocity (Figure 6b). These relative shear velocities in the pneumatophore experiments were found to be significantly lower than the values obtained from the previous studies with uniform-height dowel canopies (one-sided t-test, $\mathrm{p}<<0.01$ ).

The lower values of the relative shear velocity maxima with the real pneumatophores were not due to differences in the vertical profiles of the streamwise velocities, as concluded from Figure 6a. Hence, the lower relative shear velocities must be related to lower values of the maximum Reynolds stress in the canopy shear layer. In addition, turbulence maxima for the variable-height pneumatophore canopies were observed at about $z=1.5 h_{c}$ (Figure $5 \mathrm{~b}-\mathrm{c}$ ), as opposed to their location at the same height as the top of the canopy $\left(h_{c}\right)$ in studies with uniform-height dowels (e.g. Chen et al., 2013; Nepf and Vivoni, 2000; Poggi et al., 2004). These previous studies also show a more confined and pronounced peak of the Reynolds stress, especially for higher vegetation densities (see e.g. Figure 10 in Chen et al., 2013), coinciding with a steeper velocity gradient over the uniform-height canopies. This observation corroborates the findings by Liu et al. (2010) who observed a reduction of the maximum turbulence intensity in a double-layer dowel canopy compared to a uniform-height dowel canopy.

\section{Implications for sediment transport and deposition}

Sediment transport in emergent and submerged canopies is a combined function of hydrodynamic forces and particle properties. Elevated turbulence levels at the edges of vegetation canopies are able to sustain enhanced concentrations of suspended matter (Marion et al., 2014). Once these suspended materials are transported into the less dynamic zone within the vegetation, they may deposit depending on the settling velocity. Consequently, enhanced sediment deposition is often observed at the interface between open flows and emergent vegetation patches (Furukawa and Wolanski, 1996; Temmerman et al., 2003; Zong and Nepf, 2010), as well as within fully submerged canopies (Bouma et al., 2007; Ganthy et al., 2015). In particular, vegetated intertidal areas can be efficient sediment traps with sediment settling promoted during slack tides, (Bouma et al., 2007; Temmerman et al., 2003).

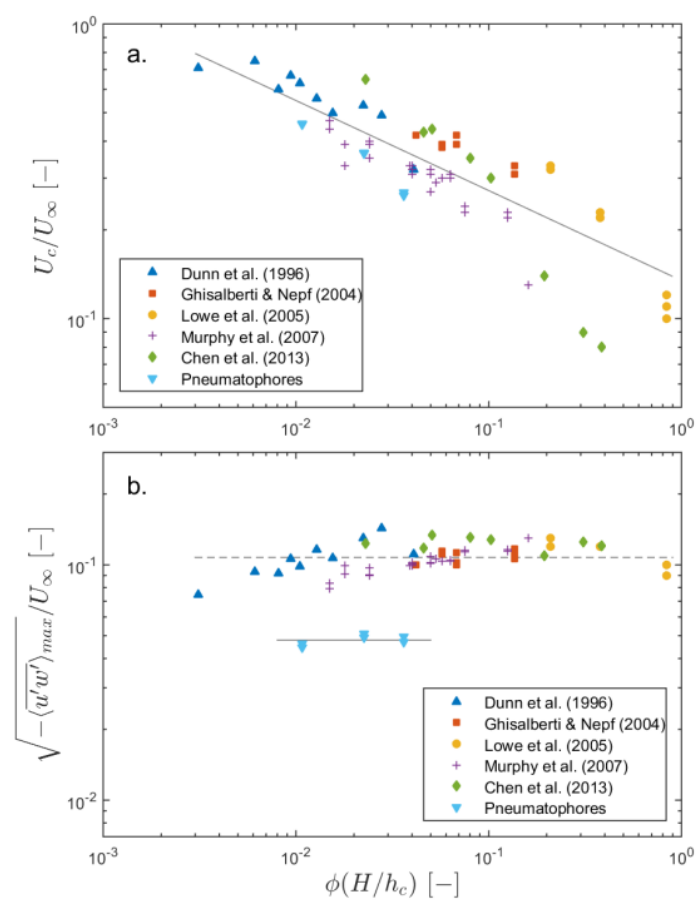

Figure 6. Data from the present work in comparison to data compiled from previous studies in artificial canopies of uniform-height dowels. (a) Ratios of the within-canopy velocity to the free-stream velocity were found to correlate significantly $(r=-0.63, p<<0.01)$ with the depth-adjusted canopy density $\varphi\left(H / h_{c}\right)$. The solid line presents the best fit for the results of both present and previous studies (Equation (1)). (b) The maximum friction velocity scaled with the free-stream velocity varied around a constant value of 0.048 (st.dev. $=0.002$ ) for the pneumatophore experiments (solid line), which is significantly lower (one-sided ttest, $\mathrm{p}<<0.01$ ) than the average of 0.108 (st.dev. $=0.014$ ) throughout the previous studies with uniform-height dowels (dashed line). 
Our findings imply that the maximum shear velocity generated over canopies of uniform-height (idealized) vegetation elements is two times higher, relative to the spatially averaged velocity at the top of the canopy, than the maximum shear velocity observed above a patch of real pneumatophores (Figure 6b). Also, the canopy shear layer was found to be less confined around the top of the canopy than in previous studies with uniform-height dowels (e.g. Chen et al., 2013; Nepf and Vivoni, 2000; Poggi et al., 2004). Hence, the findings from previous experimental studies with uniform-height canopies (e.g. Chen et al., 2013; Le Bouteiller and Venditti, 2015; Lowe et al., 2005; Nepf et al., 2007) may not necessarily be representative for inferring sediment dynamics in real aquatic canopies that are characterized by non-uniform shape and height. The reduced turbulence maximum above the pneumatophores will limit the transport of suspended matter across the pneumatophore canopy, although the greater vertical extent of the canopy shear layer may compensate for this reduction. Conversely, elevated turbulence levels within the pneumatophore canopy will affect the settling of suspended sediments. The complexity of this interplay is illustrated by the variability of accretion rates observed by Krauss et al. (2003) amongst different mangrove root structures. They argued that the higher root densities could even have promoted erosion due to enhanced turbulence levels (cf. Spenceley, 1977).

The balance between these different factors contributing to sediment transport and deposition in real pneumatophores versus dowel mimics will have to be addressed through a direct comparison of the vertical turbulence profiles, including the bed shear stresses. This comparison cannot be made with the studies available from literature, due to the differences in both canopy properties and hydrodynamic forcing across these studies. A follow-up study will examine differences in hydrodynamics between the present experiments with pneumatophores and those with a dowel canopy of the same density in order to isolate the effects of variability in both height and shape in real pneumatophores.

\section{CONCLUSIONS}

The results of this study quantified the effects of real pneumatophores on the hydrodynamics within and above these canopies. Spatially-averaged streamwise velocities within and just above the canopy (up to a height of two times the average pneumatophore height) were found to decrease monotonically with pneumatophore density, with an associated increase in flow speeds in the upper water column. The horizontal variance in streamwise velocities was found to be lowest for the average pneumatophore density, with higher variances observed for both the lower and the higher pneumatophore densities (regardless of streamwise velocities).

The larger gradient in vertical velocities associated with the greater pneumatophore densities enhanced the generation of turbulence in the upper part of the water column. Conversely, the near-bed Reynolds shear stress was found to decrease with pneumatophore density. Turbulence levels were elevated throughout a major part of the water column, compared with a plane bed scenario, due to the variable height of the pneumatophore canopies. Turbulence maxima were observed around 1.5 times the average height of the canopy.

Spatially-averaged streamwise velocity profiles for each pneumatophore density were found to collapse for different flow rates, when normalized by the velocity at the mean pneumatophore height. Similarly, the profiles of the turbulence intensity and the normalized shear velocity also collapsed for the low and high flow regimes. Hence, changes in spatially averaged vertical profiles of both the streamwise velocity and the turbulence properties due to increased flow rates were directly related with the increase of the velocity at the top of the pneumatophore canopy. Relative vertical distributions of flow and turbulence were not affected by the changing flow rates.

The ratio of the within-canopy and free-stream velocities for the pneumatophore canopies in the present experiments were consistent with the observations from previous studies that employed idealized, uniform-height dowel canopies. However, the scaled maximum friction velocity above the pneumatophores was found to be two times lower than that in uniform-height dowel canopies with a similar density. These findings suggest that results from experimental studies with uniform-height dowel canopies cannot be used unconditionally to directly infer sediment transport and deposition within real pneumatophores.

\section{ACKNOWLEDGEMENTS}

This research is funded by the Royal Society of New Zealand's Marsden Fund (14-UOW-011). We thank Christopher Eager and Dean Sandwell for their help with setting up the flume experiments, and Carolyn Lundquist and Nicola Lovett for their help with the pneumatophore collection. 


\section{REFERENCES}

Bouma, T.J., L.A. Van Duren, S. Temmerman, T. Claverie, A. Blanco-Garcia, T. Ysebaert and P.M.J. Herman. 2007. Spatial flow and sedimentation patterns within patches of epibenthic structures: Combining field, flume and modelling experiments, Continental Shelf Research, 27, 1020-1045.

Chen, Z., C. Jiang and H. Nepf. 2013. Flow adjustment at the leading edge of a submerged aquatic canopy, Water Resources Research, 49, 5537-5551.

Dunn, C., F. Lopez and M. Garcia. 1996. Mean flow and turbulence in a laboratory channel with simulated vegetation, Hydraulic Engineering Series, 51, University of Illinois, Urbana, Illinois, 148 pp.

Furukawa, K. and E. Wolanski. 1996. Sedimentation in Mangrove Forests, Mangroves and Salt Marshes, 1, 3-10.

Ganthy, F., L. Soissons, P.-G. Sauriau, R. Verney and A. Sottolichio. 2015. Effects of short flexible seagrass Zostera noltei on flow, erosion and deposition processes determined using flume experiments, Sedimentology, 62, 997-1023.

Ghisalberti, M. and H.M. Nepf. 2004. The limited growth of vegetated shear layers, Water Resources Research, 40, W07502.

Horstman, E.M., C.M. Dohmen-Janssen, P.M.F. Narra, N.J.F. Van den Berg, M. Siemerink and S.J.M.H. Hulscher. 2014. Wave attenuation in mangroves: A quantitative approach to field observations, Coastal Engineering, 94, 47-62.

Hurther, D. and U. Lemmin. 2001. A Correction Method for Turbulence Measurements with a 3D Acoustic Doppler Velocity Profiler, Journal of Atmospheric and Oceanic Technology, 18, 446458.

Järvelä, J. 2005. Effect of submerged flexible vegetation on flow structure and resistance, Journal of Hydrology, 307, 233-241.

Krauss, K.W., J.A. Allen and D.R. Cahoon. 2003. Differential rates of vertical accretion and elevation change among aerial root types in Micronesian mangrove forests, Estuarine, Coastal and Shelf Science, 56, 251-259.

Lacy, J.R. and S. Wyllie-Echeverria. 2011. The influence of current speed and vegetation density on flow structure in two macrotidal eelgrass canopies, Limnology and Oceanography, 1, 38-55.

Le Bouteiller, C. and J.G. Venditti. 2015. Sediment transport and shear stress partitioning in a vegetated flow, Water Resources Research, 51, 2901-2922.

Liénard, J., K. Lynn, N. Strigul, B.K. Norris, D. Gatziolis, J.C. Mullarney, K.R. Bryan and S.M. Henderson. 2016. Efficient three-dimensional reconstruction of aquatic vegetation geometry: Estimating morphological parameters influencing hydrodynamic drag, Estuarine, Coastal and Shelf Science, 178, 77-85.

Liu, D., P. Diplas, J.D. Fairbanks and C.C. Hodges. 2008. An experimental study of flow through rigid vegetation, Journal of Geophysical Research, 113, F04015.

Liu, D., P. Diplas, C.C. Hodges and J.D. Fairbanks. 2010. Hydrodynamics of flow through double layer rigid vegetation, Geomorphology, 116, 286-296.

Lowe, R.J., J.R. Koseff and S.G. Monismith. 2005. Oscillatory flow through submerged canopies: 1. Velocity structure, Journal of Geophysical Research, 110, C10016.

Marion, A. et al. 2014. Aquatic interfaces: a hydrodynamic and ecological perspective, Journal of Hydraulic Research, 52, 744-758.

Mazda, Y. and E. Wolanski. 2009. Hydrodynamics and modeling of water in magnrove areas. In: G.M.E. Perillo, E. Wolanski, D.R. Cahoon and M.M. Brinson (Editors), Coastal Wetlands: An integrated ecosystem approach. Elsevier, pp. 231-261.

Murphy, E., M. Ghisalberti and H.M. Nepf. 2007. Model and laboratory study of dispersion in flows with submerged vegetation, Water Resources Research, 43, W05438.

Nepf, H.M. 1999. Drag, turbulence, and diffusion in flow through emergent vegetation, Water Resources Research, 35, 479-489.

Nepf, H.M. 2012. Hydrodynamics of vegetated channels, Journal of Hydraulic Research, 50, 262-279.

Nepf, H.M., M. Ghisalberti, B. White and E. Murphy. 2007. Retention time and dispersion associated with submerged aquatic canopies, Water Resources Research, 43, W04422.

Nepf, H.M. and E.R. Vivoni. 2000. Flow structure in depth-limited, vegetated flow, Journal of Geophysical Research, 105, 28547-28557.

Nortek. 2011. Vectrino-II profiling velocimeter User Guide, Halifax, Canada, 37 pp. 
Poggi, D., A. Porporato, L. Ridolfi, J.D. Albertson and G.G. Katul. 2004. The Effect of Vegetation Density on Canopy Sub-Layer Turbulence, Boundary-Layer Meteorology, 111, 565-587.

Raupach, M.R., J.J. Finnigan and Y. Brunet. 1996. Coherent Eddies and Turbulence in Vegetation Canopies: The Mixing-Layer Analogy, Boundary-Layer Meteorology, 78, 351-382.

Rusello, P.J., A. Lohrmann, E. Siegel and T. Maddux. 2006. Improvements in acoustic doppler velocimetery, The 7th Int. Conf. on Hydroscience and Engineering, Philadelphia, USA, 1-16.

Spenceley, A.P. 1977. The role of pneumatophores in sedimentary processes, Marine Geology, 24, M31-M37.

Sukhodolova, T.A. and A.N. Sukhodolov. 2012. Vegetated mixing layer around a finite-size patch of submerged plants: 1 . Theory and field experiments, Water Resources Research, 48, W10533.

Tanino, Y. and H.M. Nepf. 2008. Lateral dispersion in random cylinder arrays at high Reynolds number, Journal of Fluid Mechanics, 600, 339-371.

Temmerman, S., G. Govers, S. Wartel and P. Meire. 2003. Spatial and temporal factors controlling short-term sedimentation in a salt and freshwater tidal marsh, scheldt estuary, Belgium, SW Netherlands, Earth Surface Processes and Landforms, 28, 739-755.

Tempest, J.A., I. Möller and T. Spencer. 2015. A review of plant-flow interactions on salt marshes: the importance of vegetation structure and plant mechanical characteristics, Wiley Interdisciplinary Reviews: Water, 2, 669-681.

Tomlinson, P.B. 1986. The botany of mangroves. Cambridge tropical biology series. Cambridge University Press, Cambridge, UK, 423 pp.

White, B.L. and H.M. Nepf. 2007. Shear instability and coherent structures in shallow flow adjacent to a porous layer, Journal of Fluid Mechanics, 593, 1-32.

Yager, E.M. and M.W. Schmeeckle. 2013. The influence of vegetation on turbulence and bed load transport, Journal of Geophysical Research, 118, 1585-1601.

Zong, L. and H. Nepf. 2010. Flow and deposition in and around a finite patch of vegetation, Geomorphology, 116, 363-372. 